\title{
Empreendedorismo Feminino: estudo comparativo entre homens e mulheres sobre motivações para empreender
}

\author{
Patrícia Bock Bandeira ${ }^{1, *}$, Marcos Vinicius Amorim², \\ Manoela Ziebell de Oliveira ${ }^{3}$
}

${ }^{1}$ http://orcid.org/0000-0002-7003-2679 / Centro de Aperfeiçoamento em Psicologia Escolar (CAPE), Brasil
${ }^{2}$ http://orcid.org/0000-0002-1050-0258 / Pontifícia Universidade Católica do Rio Grande do Sul (PUCRS), Brasil
${ }^{3}$ http://orcid.org/0000-0003-0243-5115 / Pontifícia Universidade Católica do Rio Grande do Sul (PUCRS), Brasil

O empreendedorismo vem se afirmando como uma opção de carreira cada vez mais freqüente e habitual para mulheres. Tendo isso em vista, este artigo buscou investigar as motivações e parâmetros de carreira de quatrocentos e dezesseis profissionais do Sul do Brasil, a partir do recorte de gênero. Além de questionário sociodemográfico, das características do negócio e da trajetória empreendedora, foi utilizada a Escala de Parâmetros da Carreira Caleidoscópica. Embora empreendedoras mulheres tenham destacado motivos para empreender mais amplos que a questão financeira em comparação aos empreendedores homens, tais motivos não foram os mais citados pelas empreendedoras. Tampouco foi verificada diferença significativa segundo o gênero em relação aos parâmetros da Carreira Caleidoscópica. Conclui-se que a carreira empreendedora representa uma opção de desenvolvimento profissional e propulsora de emancipação para mulheres e homens. Espera-se que este estudo contribua para o aconselhamento de carreira de empreendedores, bem como na desmistificação de estereótipos sexuais associados às motivações para o empreendedorismo.

Palavras-chave: empreendedores, motivação, desenvolvimento profissional, trabalho feminino, carreira caleidoscópica.

\section{Female Entrepreneurship: A Comparative Study of Men and Women on Motivations for Entrepreneurship}

Abstract

Entrepreneurship has been establishing itself as an increasingly frequent career choice for women. Considering this, we investigated the motivations and career parameters of 416 professionals from southern Brazil, according to their sex. In addition to a sociodemographic questionnaire, business characteristics and entrepreneurial trajectory, the Kaleidoscopic Career Parameters Scale was used. Although female entrepreneurs have highlighted reasons for choosing entrepreneurship greater than the financial issue compared to male entrepreneurs, such reasons were not the most cited by female entrepreneurs. There was no significant difference between sexes in relation to Kaleidoscopic Career parameters. It is concluded that the entrepreneurial career represents an option for professional development and emancipation for both women and men. This study is expected to contribute to entrepreneurship career counseling and the demystification of sexual stereotypes associated with entrepreneurial motivations.

Keywords: entrepreneurs, motivation, professional development, working women, kaleidoscope career

\section{Emprendimiento femenino: estudio comparativo de hombres y mujeres sobre las motivaciones para emprender}

Resumen

El emprendimiento empresarial se viene consolidando como una opción profesional cada vez más frecuente y habitual para las mujeres. Considerando ese dato, esto articulo buscó investigar las motivaciones y los parámetros de carrera de cuatrocientos dieciséis profesionales del sur de Brasil, según el sexo. Además de un cuestionario sociodemográfico, características de negocio y trayectoria empresarial, se utilizó la Escala de parámetros de carrera caleidoscópica. Si bien las empresarias han resaltado otras razones para el emprendimiento que el problema financiero en comparación con los empresarios masculinos, estas no fueron las más citadas por las empresarias. No hubo diferencias significativas según el sexo en relación con los parámetros de la carrera caleidoscópica. Se concluye que la carrera empresarial representa una opción de desarrollo profesional y propulsora de emancipación para mujeres y hombres. Se espera que este estudio contribuya a la orientación profesional sobre emprendimiento, bien como en la desmitificación de los estereotipos sexuales asociados con las motivaciones en el proceso de emprendimiento.

Palabras-clave: emprendedores, motivación, desarrollo profesional, trabajo de mujeres, carrera caleidoscópica. 
Desde os anos 1980, o aumento expressivo do exercício da atividade empreendedora por mulheres tem sido verificado ao redor do mundo, motivando o interesse de pesquisadores sobre o tema e indicando que se trata de um fenômeno sustentável, e não uma tendência passageira (Bianchi, Parisi, \& Salvatore, 2016; Global Entrepreneurship Monitor [GEM], 2017; Machado, St-Cyr, Mione, \& Alves, 2003; Martí, Porcar, \& Tur, 2014; J. H. A. Oliveira, 2017; Vale, Corrêa, \& Reis, 2014). Segundo o relatório da pesquisa GEM (2017), 274 milhões de mulheres ao redor do mundo lideravam seus próprios negócios em 2016, e dos 74 países participantes do estudo, 63 registraram aumento médio de $10 \%$ na taxa de empreendedorismo feminino durante o período de 2014 a 2016. O Brasil se destaca neste cenário, pois está entre as cinco economias com indicadores mais igualitários em relação à proporção de mulheres e homens empreendedores dentre os países avaliados, com taxa de empreendedorismo feminino apenas 1,3\% menor que a de masculino (GEM, 2017).

Visto que as mulheres direcionam uma parte maior de sua renda ao bem-estar e educação familiar, e que o empreendedorismo é apontado pela ONU como um dos melhores caminhos para o desenvolvimento de uma nação, torna-se evidente a contribuição social das mulheres empreendedoras (Serviço Brasileiro de Apoio às Micro e Pequenas Empresas [SEBRAE], 2015; Schneider, 2017). Machado et al. (2003) reforçam esta visão, alegando que o empreendedorismo feminino provoca impacto econômico (geração de empregos e renda), social (maior equilíbrio entre trabalho e família) e político (aumento da autonomia e independência econômica feminina) nos cenários em que está presente.

Outro aspecto importante é que essa expressão e escolha de carreira também é uma das formas pelas quais as mulheres podem romper com o teto de vidro encontrado nas organizações (Dean, Larsen, Ford, \& Akram, 2019; Strobino \& Teixeira, 2014; D. M. Sullivan \& Meek, 2012). O teto de vidro é uma metáfora para a barreira simbólica que dificulta a ascensão feminina aos cargos mais altos das empresas, e permite às mulheres apenas visualizarem posições de comando, as quais são impedidas de alcançar (Braun, Vierheller, \& Oliveira, 2016; Cramer, Cappelle, Andrade, \& Brito, 2012; Strobino \& Teixeira, 2014). Além da discriminação sexual e do assédio no ambiente organizacional, a expectativa social pelo cuidado com os filhos, o apoio a pais idosos, as demandas pessoais e as questões amorosas, fazem com que, com frequência, mulheres busquem novas modalidades de contratos de trabalho, ou optem pelo desligamento da empresa (Almeida \& Mota-Santos, 2018; Braun et al., 2016). Neste sentido, a escolha pelo empreendedorismo surge como uma alternativa para as mulheres, no sentido de melhor adequar seus objetivos, demandas e papéis, em contraste aos modelos tradicionais de carreira (Beatrice, 2012; Martí et al., 2014).

\section{Motivações para o Empreendedorismo Feminino}

A motivação pode ser definida como um processo psicológico básico ativado por necessidades, afetos, valores, metas e expectativas que levam um indivíduo à ação (Loiola, Gondim, Pereira, \& Ferreira, 2016). As motivações para o empreendedorismo são consideradas complexas e contextuais e, portanto, de difícil definição (Bianchi et al., 2016; Borges, Lima, \& Brito, 2017).

As pesquisas na área fazem duas distinções a respeito da motivação para abrir uma empresa: oportunidade ou necessidade (GEM, 2018; Machado et al., 2003). A motivação por oportunidade corresponde a uma decisão livre, feita em função de uma análise de mercado ou escolha deliberada, enquanto a motivação por necessidade ocorre em função da falta de espaço de inserção no mercado de trabalho. Segundo Martí et al. (2014), o empreendedorismo feminino pode ser considerado uma maneira de as mu- lheres enfrentarem o desemprego ou a pobreza aos quais são mais vulneráveis, especialmente no caso das classes econômicas menos favorecidas. No Brasil, 47\% do empreendedorismo feminino é motivado por necessidade - para os homens, esse índice é de 34\%, indicando uma das dificuldades enfrentadas por empreendedoras brasileiras (GEM, 2017). Para efeitos de comparação, em países da América do Norte a taxa média de empreendedorismo feminino por necessidade é de apenas 13\%, e, mesmo na América Latina e Caribe, a média corresponde a 30\%, colocando as brasileiras em clara desvantagem (GEM, 2017).

Nos casos em que a escolha é feita por oportunidade, o desejo por autonomia e a percepção de oportunidade de negócio são citados na literatura como os principais motivadores para o empreendedorismo entre homens e mulheres. De fato, estes foram os motivos preponderantes encontrados na pesquisa conduzida por Vale et al. (2014) com uma amostra de 170 empreendedores de Belo Horizonte, dos quais 74\% indicaram o motivo desejo de ter o próprio negócio/tornar-se independente como muito importante e $68 \%$ também consideraram a identificação de uma oportunidade como motivo muito importante para a abertura de suas empresas. O estudo de Jonathan (2011) identificou o desejo de autorrealização e autonomia financeira como os principais motivadores para uma amostra de 149 empreendedoras cariocas.

A realização pessoal foi o principal motivo para a opção pelo empreendedorismo para 30\% das participantes do estudo de Machado et al. (2003), que investigou as motivações de 90 empreendedoras do Brasil, Canadá e França. A percepção de oportunidade de mercado ficou em segundo lugar, apontada como principal razão para a escolha do empreendedorismo por 26,66\% da amostra (Machado et al., 2003). Ao enfocar somente nas respostas das participantes brasileiras do estudo, o principal motivo elencado foi a realização pessoal (26,7\%), seguida pela identificação de oportunidade de mercado $(16,7 \%)$, e pela falta de perspectiva na carreira anterior $(6,6 \%$ dos casos).

Há ainda autores que apresentam o empreendedorismo como uma alternativa para conciliação entre demandas familiares e profissionais, especialmente no caso de mães com filhos pequenos (DeMartino \& Barbato, 2003; Machado et al., 2003; M. Z. Oliveira, Barbosa, \& Gauer, 2012; Ramos \& Valdisser, 2019; D. M. Sullivan \& Meek, 2012). A família é considerada, portanto, um importante motivador para as mulheres que desejam empreender, visto que esta atividade possibilita a flexibilização de horários e consequentemente um maior envolvimento com as demandas familiares (DeMartino \& Barbato, 2003; D. M. Sullivan \& Meek, 2012; Ramos \& Valdisser, 2019).

$\mathrm{Na}$ pesquisa de DeMartino e Barbato (2003), com 497 empreendedores egressos de um programa de MBA, por exemplo, as principais motivações para a abertura do próprio negócio mencionadas pelas empreendedoras foram flexibilidade de carreira $(85,4 \%)$ e questões familiares (64,6\%). Contudo, o estudo de Martí et al. (2014) com 35 empresas lideradas por mulheres, revelou que a opção pelo empreendedorismo motivada pela conciliação entre família e trabalho apresentou correlação negativa em relação ao sucesso do negócio, indicando que empreendedoras motivadas neste sentido estariam mais propensas a descontinuarem as atividades de suas empresas.

Outra justificativa apontada por mulheres para criarem suas empresas refere-se à possibilidade de criar um ambiente de trabalho positivo, com a liberdade de escolher clientes e colaboradores e de expressar seu próprio estilo de liderança (Bianchi et al., 2016; Jonathan, 2011). O aspecto financeiro é pouco mencionado na literatura como motivação para o empreendedorismo feminino, embora isso não signifique que mulheres não queiram alcançar sucesso ou independência financeira Bernar- 
dino, Santos, \& Cardoso, 2018; (DeMartino \& Barbato, 2003; Machado et al., 2003; Jonathan, 2011; Roy \& Manna, 2014; D. M. Sullivan \& Meek, 2012). Mais especificamente, os estudos colocam que mulheres são motivadas por outros fatores que não exclusivamente a remuneração, como o equilíbrio entre família e trabalho, crescimento profissional e autonomia (DeMartino \& Barbato, 2003; Jonathan, 2011; Ramos \& Valdisser, 2019).

É importante frisar que a possibilidade de escolha pelo empreendedorismo por oportunidade ainda está fortemente associada a mulheres de classes sociais mais favorecidas, em geral com maior nível educacional (Muniz \& Veneroso, 2019). Ainda assim, Bianchi et al. (2016) alertam que essa situação pode ser encarada como um empreendedorismo por necessidade, pois com frequência corresponde a uma decisão decorrente da ausência de oportunidades ou incentivos nas organizações.

\section{O Modelo de Carreira Caleidoscópica}

A opção de mulheres com alta qualificação por deixar seus cargos nas organizações para dedicarem-se a novos formatos de trabalho ou para atender demandas de sua vida pessoal foi descrito pelas pesquisadoras norte-americanas Mainiero e Sullivan (2005) como "opt-out revolution". Na tentativa de explicar este fenômeno, as autoras desenvolveram o Modelo de Carreira Caleidoscópica, que leva em consideração o contexto em que os profissionais se encontram ao longo das etapas do ciclo de vida e os parâmetros que orientam as decisões profissionais (Mainiero \& Sullivan, 2005).

Realizando uma metáfora com o caleidoscópico, este modelo descreve como as pessoas modificam o desenho de suas carreiras de acordo com os diversos aspectos de sua trajetória. Tal qual um caleidoscópio produz imagens diferentes conforme seu tubo é girado, indivíduos alteram o "mosaico" de suas carreiras ao adequar aspectos que lhes permitam uma melhor adaptação a seus papéis, necessidades e relacionamentos (Mainiero \& Sullivan, 2005).

Assim como o caleidoscópio tem três espelhos, existem três parâmetros para a tomada de decisões de carreira, segundo o Modelo de Carreira Caleidoscópica (Bandeira, Andrade, Nora, Braga, \& Oliveira, 2019; Maniero \& Sullivan, 2005). Esses três parâmetros correspondem a: 1) Autenticidade (Authenticity) - a adequação da carreira a valores pessoais; 2) Balanço (Balance) - busca pelo equilíbrio entre trabalho e não trabalho (família, amigos e interesses pessoais); 3) Crescimento (Challenge) - necessidade de um trabalho estimulante e foco em avançar na carreira, constituindo o "ABC" do Modelo de Carreira Caleidoscópica (Bandeira et al., 2019; S. E. Sullivan, Forret, Carraher, \& Mainiero, 2009). Durante o ciclo de vida, os parâmetros se alternam, com um deles se tornando mais proeminente e orientando as decisões de carreira, ao passo que os demais parâmetros têm sua influência reduzida, assumindo um papel secundário no processo decisório. Entretanto, todos parâmetros continuam presentes e ativos, pois são relevantes para a criação do "mosaico" de vida ou de carreira de um indivíduo (Bandeira et al., 2019; S. E. Sullivan \& Baruch, 2009).

Nesse sentido, esse modelo alinha-se a aspectos intrínsecos da carreira feminina, considerada mais relacional e contextual que a masculina, dado que mulheres avaliam suas escolhas e opções pelas lentes do caleidoscópio para determinar o melhor arranjo entre seus relacionamentos, trabalhos, obstáculos e oportunidades (Henry, Foss, \& Ahl, 2016; Mainiero \& Sullivan, 2005). Sendo assim, verifica-se que a trajetória profissional de mulheres é muitas vezes interrompida ou modificada pela falta de oportunidades de carreira (necessidade de Crescimento), por demandas relacionadas a outros papéis de vida tal como a maternidade (necessidade de Balanço), ou pelo fato de o trabalho não estar alinhado a seus valores pessoais (necessidade de Autenticidade).
Para uma melhor compreensão deste fenômeno, esta pesquisa teve como objetivo investigar as motivações para o empreendedorismo e os parâmetros do Modelo de Carreira Caleidoscópica de mulheres em comparação com os homens, reduzindo assim o risco de vieses na interpretação dos resultados devido à caracterização da amostra, permitindo melhor assegurar que a orientação para determinado parâmetro seja uma especificidade do empreendedorismo feminino, e não de empreendedores em geral.

Levando em consideração a literatura analisada, denota-se que dentre os principais motivadores que levam mulheres a optarem pela carreira empreendedora estão a busca por autonomia e autorrealização (Jonathan, 2011; Machado et al., 2003; Ramos \& Valdisser, 2019; Vale et al., 2014). Sendo assim, a primeira hipótese do presente estudo prevê que mulheres empreendedoras obterão escores significativamente mais altos no parâmetro Autenticidade do Modelo de Carreira Caleidoscópica em comparação aos homens empreendedores (H1).

Além da autonomia e autorrealização, a escolha pelo empreendedorismo também é apontada por diversos autores como alternativa para que as mulheres conciliem demandas profissionais e familiares, por suporem que essa opção de carreira permite maior flexibilização de horários e criação das próprias regras de trabalho (DeMartino \& Barbato, 2003; Jonathan, 2011; Machado et al., 2003; Ramos \& Valdisser, 2019; Sullivan \& Meek, 2012). Diante disso, a segunda hipótese projeta que as mulheres empreendedoras obterão escores significativamente mais altos no parâmetro "Balanço" do Modelo de Carreira Caleidoscópica em comparação aos homens empreendedores (H2).

Por fim, as pesquisas analisadas indicam que o aspecto financeiro raramente é apontado pelas mulheres como a principal motivação para o empreendedorismo (DeMartino \& Barbato, 2003; Machado et al., 2003; D. M. Sullivan \& Meek, 2012). Por outro lado, os principais motivadores dos homens são a oportunidade de negócio e ganho financeiro, além de tenderem a tomar decisões de carreira com base em seus objetivos e ambições individuais (DeMartino \& Barbato, 2003; Machado et al., 2003; Mainiero \& Sullivan, 2005). Sendo assim, a terceira hipótese do estudo sustenta que mulheres empreendedoras obterão escores significativamente mais baixos no parâmetro "Crescimento" do Modelo de Carreira Caleidoscópica em comparação aos homens empreendedores (H3).

\section{Método}

O estudo teve delineamento quantitativo, observacional e transversal, com o objetivo principal de verificar se há diferença entre as motivações para o empreendedorismo e os parâmetros do Modelo de Carreira Caleidoscópica segundo a variável sexo e a opção pela carreira empreendedora. Ademais, a pesquisa ainda analisou as motivações que levam os indivíduos a abrirem seus próprios negócios, comparando-os por grupos segundo o sexo, faixa etária, formação profissional, renda familiar, filhos, relacionamento e, no caso de empreendedores, trajetória profissional e características da empresa.

\section{Participantes}

Para realizar este estudo comparativo, foi selecionada uma amostra composta por 416 participantes da região Sul do país, com idade entre 18 e 66 anos $(M=34,9, D P=11,3)$, dos quais $54,6 \%$ eram mulheres, e 48,6\% empreendedores. A escolaridade variou desde o ensino médio incompleto até a pós-graduação concluída. Foram convidados a participar indivíduos maiores de idade que estivessem trabalhando (empregados, autônomos e empreendedores) no momento da coleta de dados. O tama- 
nho da amostra foi definido por meio de cálculo amostral, que considerou a população total da região Sul do país, estimada em 29,644 milhões de indivíduos (Instituto Brasileiro de Geografia e Estatística [IBGE], 2017b), com margem de erro de 0,05 e nível de confiança de $95 \%$. É importante pontuar que os participantes homens e os não-empreendedores foram incluídos na amostra a fim de permitir um contraponto aos dados relativos às empreendedoras, que são o foco desta investigação.

\section{Instrumentos}

Foram utilizados três instrumentos na coleta de dados deste estudo: um questionário sociodemográfico, um questionário sobre características do negócio e trajetória empreendedora, e a Escala de Parâmetros da Carreira Caleidoscópica (Bandeira et al., 2019), descritos a seguir.

Questionário Sociodemográfico. Esse instrumento teve como objetivo avaliar os dados sociodemográficos dos respondentes. Por meio desse questionário foi possível levantar o perfil do participante, como idade, sexo, formação profissional, renda familiar, se é ou não empreendedor, se tem filhos, se está em um relacionamento estável e se reside com o/a parceiro/a.

Questionário sobre Características do Negócio e Trajetória Empreendedora. Avaliou as informações referentes ao negócio e histórico profissional dos respondentes identificados como empreendedores, tais como ramo de atuação, número de funcionários, tempo de existência, ingresso no negócio, e por que decidiu se tornar empreendedor.

Escala de Parâmetros do Modelo de Carreira Caleidoscópica. A Escala de Parâmetros do Modelo de Carreira Caleidoscópica foi desenvolvida por Sullivan et al. (2009) e adaptada ao contexto brasileiro por Bandeira et al. (2019). A versão adaptada para o contexto brasileiro conta com oito itens para avaliar o parâmetro Autenticidade (orientação para valores e significado), seis para avaliar Balanço (busca por equilíbrio entre família e trabalho) e cinco para mensurar o parâmetro Crescimento (foco para desafios e desenvolvimento profissional), compondo um instrumento com 19 itens no total. Como exemplos de itens, para avaliar Autenticidade utiliza-se expressões como "Eu espero encontrar um propósito maior para minha vida que possa combinar com quem sou" e "Se fosse necessário, eu abriria mão do sucesso ou da qualidade de vida para alcançar meus ideais". Em relação a Balanço, há exemplos como "Meu trabalho não faz sentido se eu não puder ter tempo para ficar com a minha família" e "Nada é mais importante para mim neste momento do que conseguir equilibrar meu trabalho com minhas responsabilidades familiares". Por fim, Crescimento é mensurado por meio de itens como "A maioria das pessoas me descreveria como alguém focado em seus objetivos" e "Eu constantemente procuro por novos desafios em tudo que faço". A escala/instrumento recorre a uma escala de resposta do tipo Likert de cinco pontos, variando de "Isso não me descreve" (1) para "Isso me descreve muito bem" (5). Os indicadores de confiabilidade desse instrumento adaptado ao Brasil para Autenticidade, Balanço e Crescimento foram respectivamente $\alpha=0,65$, $\alpha=0,76$, e $\alpha=0,78$ (Bandeira et al., 2019). Os índices de confiabilidade da escala original foram respectivamente $\alpha=0,76, \alpha=0,81$, e $\alpha=0,84$ (S. E. Sullivan et al., 2009).

\section{Procedimentos de Coleta de Dados e Cuidados Éticos}

A coleta de dados foi realizada por meio de um questionário on-line, disponibilizado na plataforma Qualtrics. Foram enviadas mensagens com o link para a pesquisa a indivíduos que atendessem aos critérios de inclusão da amostra, junto com uma breve descrição dos objetivos da pesquisa. Os indivíduos convidados a responder a pesquisa foram devidamente esclarecidos sobre seus objetivos e expressaram sua concordância em participar através de um termo consentimento livre e esclarecido. Todas etapas do estudo foram aprovadas pela comissão científica e pelo Comitê de Ética da instituição de origem, e seguiram as Diretrizes e Normas de Pesquisa com Seres Humanos da Resolução no 466/2012 e da Resolução no 510/2016 do Conselho Nacional de Saúde.

\section{Procedimentos de Análise dos Dados}

Após a coleta, foi realizada a análise dos dados utilizando o programa estatístico Software Statistical Package for the Social Sciences (SPSS), versão 23, por meio de análises estatísticas descritivas e testes de comparação de médias (teste-T e MANOVA) a fim de investigar diferenças entre os escores dos parâmetros da Carreira Caleidoscópica em relação ao sexo e à atividade empreendedora. Adicionalmente, também foram realizadas estatísticas descritivas, comparações entre médias e correlações para investigar se outras variáveis analisadas no estudo possuem associação entre si e em relação aos parâmetros da Carreira Caleidoscópica.

\section{Resultados}

\section{Perfil da Amostra}

As análises descritivas indicaram que mais da metade dos participantes estava em um relacionamento estável (72\%), dos quais $70 \%$ residiam com o/a parceiro/a, no momento da coleta de dados. Apenas $32 \%$ da amostra relatou ter filhos, com apenas um descendente em metade destes casos. Quanto à formação, $21,6 \%$ não havia concluído o ensino superior, $41,3 \%$ tinham o terceiro grau completo e $37 \%$ tinham realizado pós-graduação. Corroborando com os dados da Pesquisa Nacional por Amostra de Domicílio - Pnad (IBGE, 2015), mulheres apresentaram nível de escolaridade significativamente superior ao dos homens $\left(t=-3,825 ; p<0,001, \eta^{2}=0,4\right)$, em que 44,1\% tinham pós-graduação concluída ante um índice de 29,6\% dos homens.

A renda familiar média dos participantes estava na faixa entre $\mathrm{R} \$ 5.000$ a $\mathrm{R} \$ 10.000$ mensais. Profissionais com filhos apresentaram renda média familiar significativamente superior ao de profissionais sem filhos $\left[F(387,1)=7,031 ; p=0,008, \eta^{2}=0,3\right]$. Como esperado e reforçado por pesquisas na área (IBGE, 2015), houve correlação positiva entre o nível de formação dos participantes e sua renda familiar média $(r=0,24 ; p<0,001)$, tendo os profissionais com ensino médio incompleto faixa de renda $57 \%$ menor do que profissionais com pós-graduação. Apesar deste dado, verificou-se diferenças significativas na renda familiar segundo o sexo $\left[F(387,1)=5,17 ; p=0,024, \eta^{2}=0,2\right]$, tendo as mulheres registrado média salarial $8 \%$ menor que a de homens, embora seus níveis de formação tenham sido significativamente superiores $\left(t=-3,825 ; p<0,001, \eta^{2}=0,4\right)$. Tal aspecto pode ser explicado pelo fato de as mulheres estarem mais presentes em campos de atuação menos valorizados no mercado, terem jornadas de trabalho reduzidas para dedicarem-se aos cuidados dos filhos e do lar, além de sofrerem maior discriminação no ambiente de trabalho (Muniz \& Veneroso, 2019; Nascimento, 2016, Stein, Sulzbach, \& Bartels, 2015). O indicador de 8\% corrobora os resultados encontrados por Muniz e Veneroso (2019) e Stein et al. (2015) sobre diferenças salariais entre os sexos segundo a classe de renda, dado que a amostra deste estudo foi composta principalmente por participantes com ensino superior completo, indicando um extrato da população de maior nível educacional e social.

$\mathrm{Na}$ amostra analisada, 48,6\% dos participantes eram em- 
preendedores, dos quais 55\% eram mulheres. Destas, $44,6 \%$ tinham filhos e $63,4 \%$ estavam em um relacionamento estável em que residiam com o/a parceiro/a. Em relação aos empreendedores homens, $31,1 \%$ tinham filhos e $55,5 \%$ estavam em um relacionamento estável em que moravam com a/o companheira/o. A renda média e a escolaridade entre empreendedores homens e mulheres não apresentou diferença significativa, bem como entre profissionais empreendedores e não-empreendedores.

\section{Características dos Negócios e Trajetória Empreendedora}

A maior parte dos negócios foi fundada pelos próprios empreendedores $(77,7 \%)$, está formalizada $(74,6 \%)$ e possui até dois sócios (76,7\%). Em relação ao tempo de existência, 42,8\% das empresas tinham até dois anos, 29,3\% de três a 10 anos, e 27,9\% de 11 a 40 anos.

Dos respondentes empreendedores, $72,8 \%$ gerenciavam apenas um negócio e 13,4\% haviam atuado exclusivamente como empreendedores ao longo de suas carreiras, enquanto os demais haviam tido experiências anteriores como colaboradores em outras instituições. Ainda em relação à trajetória profissional, 31,7\% dos empresários já haviam tido outro negócio anteriormente. Nenhuma destas variáveis apresentou diferenças significativas em relação ao sexo do respondente.

A amostra foi composta por uma maioria de microempresários, visto que 33,8\% não tinha funcionários contratados, e 40,8\% contava com um a quatro colaboradores em suas empresas. Somente $8,5 \%$ dos respondentes gerenciavam empresas com mais de 20 funcionários. Ao compararmos as médias entre empreendedores homens e mulheres, há uma diferença significativa neste aspecto: negócios gerenciados por mulheres têm em média 4,1 funcionários, enquanto os dos homens possuíam em média 8,2 funcionários $\left(t=2,195 ; p=0,029, \eta^{2}=0,3\right)$.

Considerando a carga horária de trabalho, 28,5\% dos empreendedores dedicam menos de 20 horas semanais ao negócio, $31,5 \%$ dedicam de 21 a 40 horas semanais e $40 \%$ despendem mais de 40 horas por semana para gerenciar suas empresas. Profissionais que trabalham exclusivamente em seu negócio (55,9\% do total) dedicam uma carga horária média significativamente maior (45 horas por semana) em comparação aos empreendedores que também possuem outra atividade laboral, como emprego na iniciativa privada ou cargo público $[F(190,5)=14,022 ; p<0,001]$. O percentual da contribuição do negócio na renda familiar também foi significativamente maior para empreendedores dedicados exclusivamente a esta atividade $[F(190,5)=7,250 ; p=0,008]$, representando uma média de contribuição na faixa de 60 a $80 \%$ da renda familiar total. A média do percentual de contribuição do negócio para a renda familiar das empreendedoras foi significativamente menor do que o de empreendedores, com diferença de $20 \%$ $\left[F(190,1)=5,407 ; p=0,021, \eta^{2}=0,3\right]$.

Organizações com CNPJ apresentaram médias significativamente maiores para tempo de existência $[F(1,190)=7,25 ; p=0,008$, $\left.M=10,35, \eta^{2}=0,5\right]$, número de funcionários $[F(190,1)=8,012$; $\left.p=0,005, M=7,55, \eta^{2}=0,6\right]$, carga horária semanal média dedicada pelo empresário $\left[F(190,1)=31,907 ; p<0,001, M=41,21, \eta^{2}\right.$ $=1]$. Houve correlação positiva significativa entre estas variáveis e a renda familiar do empreendedor, conforme a Tabela 1, e a média de percentual de contribuição do negócio para a renda familiar foi $30 \%$ maior em relação a empresas não formalizadas $\left[F(190,1)=23,262 ; p<0,001, \eta^{2}=0,8\right]$.

\section{Motivações para a Carreira Empreendedora}

Ao preencherem o questionário, os empreendedores deve-
Tabela 1

\begin{tabular}{|c|c|c|c|c|c|}
\hline $\mathrm{N}$ & Características & 1 & 2 & 3 & 4 \\
\hline 1 & Tempo de existência do negócio & 1 & & & \\
\hline 2 & Número de Funcionários & $0,387^{* *}$ & 1 & & \\
\hline 3 & $\begin{array}{l}\text { Carga horária semanal dedicada } \\
\text { ao negócio }\end{array}$ & $0,217^{*}$ & $0,308^{* *}$ & 1 & \\
\hline 4 & Renda Familiar & $0,201 *$ & $0,252^{* *}$ & $0,189 *$ & 1 \\
\hline
\end{tabular}

significativo para $p<0,01 \mathrm{e}^{* *}$ significativo para $p<0,001$

riam selecionar até três razões pelas quais decidiram abrir seus negócios, de um total de 17 afirmativas criadas com base na literatura da área - a $18^{a}$ opção era aberta e permitia que o respondente incluísse um motivo caso não o identificasse entre as demais afirmações. Os principais motivos selecionados por mulheres e homens foram similares, conforme indicado na Tabela 2. Para elas, destaca-se em primeiro lugar atuar de forma alinhada a valores pessoais (36,6\%), seguido pelo desejo por maior autonomia $(35,7 \%)$ e pela identificação de uma oportunidade de negócio (30,4\%). Para eles, querer trabalhar com maior autonomia veio na primeira posição (40\%), seguido por identificação de uma oportunidade de negócio $(37,8 \%)$. Seguir a carreira dos sonhos também foi uma das razões mais destacadas para mulheres $(25,9 \%)$ e homens $(25,6 \%)$, ocupando o quarto e o terceiro lugar, respectivamente. Atuar de forma alinhada a valores pessoais ocupou o quinto lugar na ordem masculina (foi selecionado por $20 \%$ dos homens empreendedores), e, portanto, foi o item com maior discrepância entre homens e mulheres, registrando uma diferença de 16,6\%. Estes achados corroboram a pesquisa de Machado et al. (2003) e Jonathan (2011) que apontaram realização pessoal, identificação de uma oportunidade de negócio e autorrealização como os principais motivos para as mulheres iniciarem um negócio.

No entanto, os dados encontrados também ratificam o fato de as mulheres tenderem a valorizar aspectos mais amplos que a questão financeira em comparação aos homens para abrir sua própria empresa, corroborando com os trabalhos de DeMartino e Barbato (2003), D. M. Sullivan e Meek (2012), e Roy e Manna (2014). As razões mais frequentemente citadas por mulheres em contraste com os homens foram a atuação segundo os valores pessoais (diferença de 16,6\%), equilíbrio entre família e trabalho (diferença de $7,4 \%$ ) e a liberdade para escolher como trabalhar (diferença de 4,8\%).

Por outro lado, a identificação de uma oportunidade de negócio (diferença de 7,4\%), complementação de renda (diferença de $7,3 \%$ ) e maior ganho financeiro (diferença de 6,8\%) são razões apontadas mais frequentemente pelos homens do que por mulheres, seguindo a tendência apontada nos trabalhos de DeMartino e Barbato (2003) e Sullivan e Meek (2012) de que homens tendem a ser mais motivados por questões financeiras quando optam por abrir seus negócios. Ademais, o fato de mulheres citarem mais frequentemente buscar equilíbrio entre família e trabalho corrobora com a ideia de que elas tendem a valorizar mais os aspectos familiares ao decidir empreender. No entanto, é importante destacar que esse motivo ficou em $10^{\circ}$ lugar - ou seja, não ocupa lugar de destaque na ordem dos motivos que levam as mulheres a abrirem suas empresas.

\section{Parâmetros da Carreira Caleidoscópica}

Ao se avaliar os escores dos parâmetros da Carreira Caleidoscópica, verifica-se que 45,7\% dos respondentes têm Crescimento como o parâmetro mais influente e que orienta suas decisões de carreira. Entre os empreendedores, este parâmetro é ainda mais evidente, orientando $50 \%$ deste público, embora em indivíduos não-empreendedores, este também seja o parâmetro mais proe- 
Tabela 2

Análise dos motivos para empreender entre homens e mulheres

\begin{tabular}{|c|c|c|c|c|c|c|c|}
\hline Motivo & $\begin{array}{l}\% \text { Total de } \\
\text { Empreend. }\end{array}$ & Posição Geral & $\begin{array}{l}\text { \% Empreend. } \\
\text { Mulheres }\end{array}$ & Posição Mulheres & $\begin{array}{l}\% \text { Empreend } \\
\text { Homens }\end{array}$ & Posição Homens & $\begin{array}{c}\text { Mulheres em } \\
\text { relação aos } \\
\text { homens }\end{array}$ \\
\hline $\begin{array}{l}\text { Queria trabalhar } \\
\text { com maior auto- } \\
\text { nomia. }\end{array}$ & $37,6 \%$ & 1 & $35,7 \%$ & 2 & $40,0 \%$ & 1 & $-4,3 \%$ \\
\hline $\begin{array}{l}\text { Identifiquei uma } \\
\text { oportunidade de } \\
\text { negócio. }\end{array}$ & $33,7 \%$ & 2 & $30,4 \%$ & 3 & $37,8 \%$ & 2 & $-7,4 \%$ \\
\hline $\begin{array}{l}\text { Atuar de forma } \\
\text { alinhada aos meus } \\
\text { valores pessoais. }\end{array}$ & $29,2 \%$ & 3 & $36,6 \%$ & 1 & $20,0 \%$ & 5 & $16,6 \%$ \\
\hline $\begin{array}{l}\text { Seguir a carreira } \\
\text { dos meus sonhos. }\end{array}$ & $25,7 \%$ & 4 & $25,9 \%$ & 4 & $25,6 \%$ & 3 & $0,3 \%$ \\
\hline $\begin{array}{l}\text { Liberdade para } \\
\text { escolher como } \\
\text { trabalhar. }\end{array}$ & $19,3 \%$ & 5 & $21,4 \%$ & 5 & $16,7 \%$ & 7 & $4,8 \%$ \\
\hline $\begin{array}{l}\text { Para ter maiores } \\
\text { ganhos finan- } \\
\text { ceiros. }\end{array}$ & $17,3 \%$ & 6 & $14,3 \%$ & 6 & $21,1 \%$ & 4 & $-6,8 \%$ \\
\hline $\begin{array}{l}\text { Ter maior } \\
\text { controle sobre } \\
\text { meus horários/ } \\
\text { flexibilização de } \\
\text { horários. }\end{array}$ & $15,3 \%$ & 7 & $12,5 \%$ & 7 & $18,9 \%$ & 6 & $-6,4 \%$ \\
\hline $\begin{array}{l}\text { Para crescer pro- } \\
\text { fissionalmente. }\end{array}$ & $13,9 \%$ & 8 & $11,6 \%$ & 8 & $16,7 \%$ & 8 & $-5,1 \%$ \\
\hline $\begin{array}{l}\text { Conquistar minha } \\
\text { independência } \\
\text { financeira. }\end{array}$ & $12,4 \%$ & 9 & $11,6 \%$ & 9 & $13,3 \%$ & 10 & $-1,7 \%$ \\
\hline $\begin{array}{l}\text { Complementação } \\
\text { de renda. }\end{array}$ & $10,4 \%$ & 10 & $7,1 \%$ & 12 & $14,4 \%$ & 9 & $-7,3 \%$ \\
\hline $\begin{array}{l}\text { Queria exercer } \\
\text { meu estilo próprio } \\
\text { de liderar. }\end{array}$ & $8,9 \%$ & 12 & $7,1 \%$ & 11 & $11,1 \%$ & 13 & $-4,0 \%$ \\
\hline $\begin{array}{l}\text { Estava desem- } \\
\text { pregado(a) e } \\
\text { precisava de um } \\
\text { trabalho. }\end{array}$ & $8,9 \%$ & 11 & $9,8 \%$ & 13 & $7,8 \%$ & 11 & $2,0 \%$ \\
\hline $\begin{array}{l}\text { Equilíbrio entre } \\
\text { família-trabalho }\end{array}$ & $7,4 \%$ & 13 & $10,7 \%$ & 10 & $3,3 \%$ & 15 & $7,4 \%$ \\
\hline $\begin{array}{l}\text { Criar um ambien- } \\
\text { te de trabalho } \\
\text { positivo }\end{array}$ & $6,9 \%$ & 14 & $4,5 \%$ & 15 & $10,0 \%$ & 12 & $-5,5 \%$ \\
\hline $\begin{array}{l}\text { Não tinha boas } \\
\text { perspectivas em } \\
\text { meu emprego } \\
\text { anterior. }\end{array}$ & $5,4 \%$ & 15 & $7,1 \%$ & 14 & $3,3 \%$ & 16 & $3,8 \%$ \\
\hline $\begin{array}{l}\text { Conciliar com } \\
\text { meus estudos. }\end{array}$ & $4,0 \%$ & 16 & $3,6 \%$ & 18 & $4,4 \%$ & 14 & $-0,9 \%$ \\
\hline $\begin{array}{l}\text { Porque discordava } \\
\text { da forma com } \\
\text { que meu superior } \\
\text { administrava seu } \\
\text { negócio no meu } \\
\text { emprego anterior. }\end{array}$ & $4,0 \%$ & 17 & $4,5 \%$ & 16 & $3,3 \%$ & 17 & $1,1 \%$ \\
\hline Outro & $4,0 \%$ & 18 & $4,5 \%$ & 17 & $3,3 \%$ & 18 & $1,1 \%$ \\
\hline
\end{tabular}

minente (41,6\%), mesmo que não de forma tão acentuada, como pode ser observado na Tabela 3.

Tabela 3

Parâmetros da Carreira Caleidoscópica segundo perfil da amostra

\begin{tabular}{cccc}
\hline Parâmetro & Empreendedores & $\begin{array}{c}\text { Não- } \\
\text { Empreendedores }\end{array}$ & Amostra Total \\
\hline Autenticidade & $21,3 \%$ & $34,1 \%$ & $27,9 \%$ \\
Balanço & $28,7 \%$ & $24,3 \%$ & $26,4 \%$ \\
Crescimento & $50 \%$ & $41,6 \%$ & $45,7 \%$ \\
\hline
\end{tabular}

De fato, ao comparar as médias obtidas em relação ao parâmetro Crescimento, foi possível observar diferença significativa entre indivíduos empreendedores $(M=3,86)$ e não-empreendedores $\left[M=3,53 ; F(416,1)=15,150 ; p<0,001, \eta^{2}=0,4\right]$. No entanto, não foram encontradas diferenças significativas entre mulheres e homens, empreendedores ou não. Em relação aos parâmetros Autenticidade e Balanço, não foram encontradas diferenças significativas entre os grupos analisados.

Mulheres $(M=3,69, D P=0,88)$ e homens $(M=3,72, D P=$ $0,85)$ tiveram médias mais elevadas no parâmetro Crescimento, 
seguido por Autenticidade (MMulher $=3,56, D P=0,66$; MHomem $=3,46, D P=0,79)$ e então Balanço (MMulher $=3,28, D P=$ $0,88$; Homem $=3,23, D P=0,88)$, demonstrando que também não houve diferença na ordem de proeminência dos parâmetros segundo o sexo. Em relação à frequência, 66 das mulheres participantes $(29 \%)$ tiveram o parâmetro Autenticidade como mais proeminente, 60 o parâmetro Balanço (26,4\%), e 101 o parâmetro Crescimento (44,4\%). Dos homens, 50 dos respondentes tiveram Autenticidade como parâmetro proeminente (26,4\%), 50 Balanço (26,4\%), e 89 o parâmetro Crescimento (47\%).

Em relação às variáveis sociodemográficas, verificou-se que profissionais em relacionamentos estáveis obtiveram escores mais baixos para o parâmetro Autenticidade $[M=3,43, D P=0,7$; t (416) $\left.=-3,303, p=0,001, \eta^{2}=0,4\right]$ e mais elevados para Balanço $[M=3,33$, $\left.D P=0,88 ; t(416)=2,644, p=0,009, \eta^{2}=0,3\right]$. O mesmo ocorreu com profissionais com filhos, que também apresentaram escores significativamente mais baixos para Autenticidade $[M=3,31, D P=$ 0,$\left.729 ; t(416)=-3,800 ; p<0,001, \eta^{2}=0,4\right]$ e mais altos em relação a Balanço $\left[M=3,49, D P=0,88 ; t(416)=3,774 ; p<0,001, \eta^{2}=0,4\right]$. Tais resultados podem estar associados ao fato de que o parâmetro Autenticidade seja associado a aspectos mais individualistas e de realização pessoal e, portanto, têm sua importância reduzida à medida que o papel familiar ou de cônjuge tornam-se mais salientes (Braun et al., 2016). Este resultado corrobora com o estudo de DeMartino e Barbato (2003), em que empreendedores casados ou com filhos apresentaram diferença significativa nas motivações para o empreendedorismo ligadas a conciliação com demandas familiares em comparação com aqueles que eram solteiros ou sem filhos, que priorizavam a motivação por questões financeiras.

Ainda houve correlação inversa significativa entre o parâmetro Autenticidade e a idade dos sujeitos, indicando que indivíduos mais jovens tendem a ter este parâmetro em nível mais elevado $[r(416)=-0,197, p<0,001]$. Isso pode ocorrer em razão de que profissionais em início de carreira tendem a ser mais idealistas em relação à trajetória profissional (Falaster, Ferreira, \& Reis, 2015). Além disso, a maioria dos respondentes com até 30 anos não tinha filhos $(97,1 \%)$ e não residia com o parceiro $(69,5 \%)$, o que minimizaria aspectos associados a Balanço e também a busca por maior ganho financeiro para assegurar o sustento da família, este último associado ao parâmetro Crescimento (Henry et al., 2016; Maniero \& Sullivan, 2005; Vale et al., 2014).

A variável renda familiar teve correlação inversa com o parâmetro Autenticidade $[r(416)=-0,215, p<0,001]$. Neste sentido, é possível inferir que profissionais com menor rendimento sintam mais falta em exercer atividades alinhadas a seus valores pessoais, uma vez que as restrições econômicas derivadas de baixo nível salarial possam levá-los a assumir trabalhos por necessidade, mas que não sejam consonantes com seus ideais (Vale et al., 2014), ou que tenham como prioridade atuar profissionalmente em atividades que permitam maior realização pessoal, mesmo que esta escolha implique em uma menor remuneração.

Foi identificada ainda correlação positiva entre o nível de formação profissional com Crescimento $[r$ (416) $=$ $0,188, p<0,001]$, em que quanto maior a formação profissional do sujeito, maior a sua orientação para este parâmetro. É provável que a própria busca por maior qualificação profissional seja uma expressão deste parâmetro, dado que pessoas com maior qualificação tendem a ter melhores oportunidades de trabalho (IBGE, 2015; Mainiero \& Sullivan, 2005).

Dentre os empreendedores, houve correlação positiva com o número de negócios gerenciados e o Crescimento $[r$ $(202)=0,175 ; p=0,013]$ e correlação inversa em relação à Balanço $[r(202)=-0,180 ; p=0,01]$. Estes resultados podem indicar que empreendedores com ênfase em Crescimento prefiram gerenciar um maior número de empresas em busca de maiores resultados; já empresários com médias mais elevadas em Balanço tenderiam a priorizar o tempo com a família, preferindo ter um número menor de empresas para gerenciar. Neste sentido, verificou-se correlação positiva entre Crescimento e carga horária semanal dedicada ao negócio $[r(202)=0,157 ; p=0,027]$.

O percentual da contribuição do negócio para a renda familiar dos empreendedores teve correlação positiva em relação ao parâmetro Crescimento $[r(193)=0,145 ; p=0,044]$ e negativa para Autenticidade $[r(193)=-0,168 ; p=0,019]$. Isso pode sinalizar que indivíduos com orientação para Crescimento busquem maior nível de ganho financeiro, enquanto indivíduos com médias mais elevadas para Autenticidade possam valorizar outros aspectos associados à atividade empreendedora não necessariamente atrelados a reconhecimento pecuniário, como a dedicação a uma causa ou o empreendedorismo social por exemplo.

\section{Discussão}

No tocante ao objetivo deste estudo, não foram encontradas diferenças significativas entre as médias de mulheres e homens, para quaisquer parâmetros que compõem o Modelo de Carreira Caleidoscópica. Ademais, as motivações para a abertura do próprio negócio segundo o sexo foram semelhantes entre si. Entre as principais razões elencadas de mulheres e homens estão o desejo por maior autonomia, identificação de uma oportunidade de negócio, atuação de forma alinhada a valores pessoais e a busca pela carreira dos sonhos. Estes achados vão ao encontro dos resultados encontrados de outras pesquisas empíricas da área (Jonathan, 2011; Machado et al., 2003; Vale et al., 2014) mas que consideraram apenas mulheres em suas amostras, o que dificulta adotar um posicionamento claro se as motivações para o empreendedorismo identificadas nas pesquisas eram específicas da realidade feminina ou se correspondiam a um viés de pesquisa em função do perfil amostral. Por esta razão, optou-se nesse estudo comparar os resultados de empreendedores dos dois sexos, em que não foram encontradas diferenças significativas com relação aos parâmetros do Modelo de Carreira Caleidoscópica, tampouco com os motivos indicados sobre o que os levou a empreender.

Os resultados, portanto, corroboram com uma perspectiva contextual a respeito das razões para o empreendedorismo, em que diferenças entre as motivações para empreender e os parâmetros que orientam a tomada de decisões de carreira não podem ser atribuídos essencialmente ao sexo, mas possivelmente a outras variáveis, tais como o contexto em que o indivíduo está inserido, seu histórico profissional e suas características pessoais. Segundo Beatrice (2012), as empreendedoras não podem ser consideradas como um grupo homogêneo, e levar em conta uma única variável para entender como mulheres optam pelo empreendedorismo seria uma simplificação inadequada.

No entanto, os resultados também ratificaram que mulheres têm motivações que vão além das aspirações financeiras ao iniciarem seus negócios em comparação aos homens, resultado apontado em outras pesquisas da área (DeMartino \& Barbato, 2003; Jonathan, 2011; Ramos \& Valdisser, 2019; Roy \& Manna, 2014; D. M. Sullivan \& Meek, 2012). Homens citaram com maior frequência terem motivações financeiras para abrir seus negócios em comparação com mulheres, que por sua vez elencaram outras motivações, como a busca por equilíbrio família-trabalho e liberdade em escolher como trabalhar, mais frequentemente que indivíduos do sexo masculino. Diante desta constatação, pode-se inferir que aspectos ligados à divisão sexual do trabalho e expectativas sociais associadas à responsabilidade pelo cuidado com a família e o lar exercem influência na escolha do empreendedoris- 
mo por mulheres (Carloto \& Nogueira, 2019; Sousa \& Guedes, 2016), conforme reforçado pela frequente justificativa de que abriram seus negócios com o objetivo de promover maior equilíbrio família e trabalho, em comparação com os homens. Contudo, no caso masculino, também é possível observar o impacto das expectativas sociais, no sentido de serem os provedores e responsáveis pelo sustento da família, visto que consideraram mais aspectos financeiros ao empreender, em comparação com as participantes do sexo feminino (Carloto \& Nogueira, 2019; Sousa \& Guedes, 2016). Ainda assim, os resultados deste e outros estudos reforçam que as motivações principais que levam homens e mulheres a empreender se assemelham, indicando que as expectativas sociais exercem uma influência menor nesta tomada de decisão em comparação com a busca por realização pessoal e a identificação de oportunidades de negócio (GEM, 2018; Matte et al., 2019).

Essa explicação contribui para esclarecer as aparentes contradições entre pesquisas da área, em que algumas apontam a realização pessoal e identificação de uma oportunidade de negócio como as principais motivações para o empreendedorismo feminino (Jonathan, 2011; Machado et al., 2003; Vale et al., 2014) enquanto outras salientam a importância do equilíbrio família-trabalho e da liberdade em escolher como trabalhar (DeMartino \& Barbato, 2003; Machado et al., 2003; Sullivan \& Meek, 2012). De acordo com os resultados do presente estudo, o primeiro caso representa as principais motivações para o empreendedorismo em mulheres (no entanto, para homens também), enquanto o segundo representa as principais diferenças das motivações para o empreendedorismo feminino em comparação com o masculino. Tais resultados colocam em xeque estereótipos associados ao empreendedorismo feminino, corroborando com a pesquisa Global Entrepreneurship Monitor (2018) e o estudo de Matte et al. (2019), que indicam que as motivações para o empreendedorismo feminino e masculino são similares.

Ainda, ao comparar empreendedores com profissionais que não possuem o próprio negócio, os resultados indicaram que os primeiros possuem médias do parâmetro Crescimento significativamente maiores do que não empreendedores. Tal resultado denota a maior necessidade dos empresários por superar desafios, pela busca por um trabalho estimulante e pelo foco em avançar na carreira, corroborando com outros estudos (Mainiero \& Sullivan, 2005; I. R. Oliveira, Camargo, Feijó, Campos, \& Goulart, 2016; S. E. Sullivan \& Baruch, 2009). Mesmo que tais características sejam associadas a traços estereotipadamente masculinos (Ahl \& Marlow, 2012; Cramer et al., 2012; Gupta, Wieland, \& Turban, 2019; Monteiro, Silveiro, \& Daniel, 2015), não foi encontrada diferença significativa segundo o sexo para este parâmetro, reforçando os demais resultados encontrados, visto que tais aspirações não estão associadas ao sexo, mas às demandas inerentes a esta atividade.

\section{Considerações Finais}

Este estudo teve como objetivo verificar se há diferença entre as motivações para o empreendedorismo e os parâmetros da Carreira Caleidoscópica segundo o sexo do indivíduo. Os resultados encontrados não identificaram diferença significativa segundo esta variável, contribuindo para desmistificar a ideia de que as motivações para o empreendedorismo feminino sejam essencialmente diferentes do masculino (Bianchi et al., 2016; Jonathan, 2011; Machado et al., 2003).

As mulheres e homens empreendedores participantes deste estudo relataram como motivos principais para a abertura de seus negócios a identificação de oportunidades de trabalho, o desejo por autonomia e a atuação segundo seus valores pessoais. Neste sentido, a carreira empreendedora destaca-se como espaço de de- senvolvimento e emancipação em relação à atividade profissional dos indivíduos, independente do sexo. Ainda que mulheres possam ter destacado também outros motivos para empreender mais amplos que a questão financeira em comparação aos homens - como é o caso da busca por equilíbrio família-trabalho - é importante destacar que estes motivos não foram os mais frequentemente citados pelas empreendedoras. Não foi tampouco encontrada diferença significativa entre os parâmetros da Carreira Caleidoscópica segundo o sexo - somente em relação aos empreendedores, que possuem médias em Crescimento significativamente mais elevadas que profissionais que não possuem seu próprio negócio, reforçando ainda mais o direcionamento para desafios e avanço profissional deste perfil de público (I. R. Oliveira et al., 2016).

Mesmo que o estudo tenha contribuído para minimizar concepções de que o empreendedorismo feminino seja essencialmente diferente do masculino, é necessário pontuar algumas limitações da pesquisa. Uma delas refere-se à escolha do método de amostragem por conveniência, em que os resultados encontrados não são passíveis de generalização, e podem estar relacionados a especificidades da amostra investigada, especialmente em relação ao contexto cultural dos locais de procedência dos participantes. Portanto, sugere-se a realização de novos estudos envolvendo empreendedores e o Modelo de Carreira Caleidoscópica com o intuito de diversificar o perfil populacional da amostra. Ademais, pesquisas de cunho qualitativo também podem ser úteis para complementar o entendimento deste fenômeno, dadas as limitações inerentes à natureza quantitativa desta pesquisa. Além disso, o fato de os instrumentos da pesquisa serem baseados na autopercepção dos respondentes, pode envolver vieses cognitivos e motivacionais, como aspectos ligados a desejabilidade social.

Espera-se que os resultados obtidos contribuam para uma maior conscientização e reforço da adoção de políticas e programas mais adequados à realidade do empreendedorismo feminino, além de contribuir para desmistificar as razões que levam as mulheres a empreender. Ao contestar a ideia de que as motivações para o empreendedorismo feminino sejam essencialmente diferentes do masculino, abre-se a oportunidade de analisar as múltiplas possibilidades de interrelações entre a trajetória individual dos sujeitos e as expectativas sociais existentes, ampliando o estudo deste fenômeno para além de uma visão simplista de diferença entre os sexos (Ahl, 2006; Marlow, 2014). Além disso, espera-se que o maior esclarecimento das razões para empreender e a análise dos parâmetros segundo o Modelo de Carreira Caleidoscópica possam favorecer práticas e decisões relacionadas à carreira mais assertivas e alinhadas às reais aspirações de empreendedores e empreendedoras.

\section{Referências}

Ahl, H. J. (2006). Why Research on Women Entrepreneurs Needs New Directions. Entrepreneurship Theory and Practice, 30(5), 595-621. https://doi. org/10.1111/i.1540-6520.2006.00138.x

Ahl, H., \& Marlow, S. (2012). Exploring the Dynamics of Gender, Feminism and Entrepreneurship: Advancing debate to escape a dead end?. Organization, 19(5), 543-562. https://doi.org/10.1177/1350508412448695

Almeida, V. C., \& Mota-Santos, C. M. (2018). Trabalho, Carreira e Maternidade: Perspectivas e dilemas de mulheres profissionais contemporâneas. Administração: Ensino e Pesquisa. 19(3), 583-605. Recuperado de https://bit. ly/2AbDjVX

Bandeira, P. B., Andrade, A. L., Nora, M. C. V., Braga, M. M., \& Oliveira, M. Z. (2019). Adaptação e Evidências de Validade da Escala de Parâmetros da Carreira Caleidoscópica. Revista Brasileira de Orientação Profissional, 20(1), 103 114. https://doi.org/10.26707/1984-7270/2019v20n1p103

Beatrice, A. (2012). Why Women Enter into Entrepreneurship?. An emerging conceptual framework based on the Peruvian case. Journal of Women's Entrepreneurship and Education, 3(4), 43-63. Recuperado de https://www. library.ien.bg.ac.rs/index.php/jwee/article/view/96 
Bernardino, S., Santos, J. D., \& Cardoso, C. (2018). Empreender no feminino em Portugal: Motivações e obstáculos. European Journal of Applied Business Management, 1(4), 101-117. Recuperado de https:/ /recipp.ipp.pt/ handle/10400.22/11402

Bianchi, M., Parisi, V., \& Salvatore, R. (2016). Female entrepreneurs: Motivations and constraints. An Italian regional study. International Journal of Gender and Entrepreneurship, 8(3), 198-220. https://doi.org/10.1108/IJGE-08-2015-0029

Borges, A. F., Lima, J. B., \& Brito, M. J. (2017). Fundamentos da Pesquisa em Empreendedorismo: Aspectos Conceituais, Teóricos, Ontológicos e Epistemológicos. EnANPAD: São Paulo. Recuperado de https://bit.ly/3dJuili

Braun, A. C., Vierheller, B., \& Oliveira, M. Z. (2016). Conflito Trabalho-Família em Executivos: Uma revisão sistemática de 2009 a 2014. Revista Brasileira de Orientação Profissional, 17(1), 19-30. Recuperado de https://www.redalyc.org/ pdf/2030/203049524004.pdf

Carloto, C. M.; Nogueira, B. W. F. (2019). Família, gênero e proteção social. Revista em Pauta, 16(42), 49-64. https://doi.org/10.12957/rep.2018.39407

Conselho Nacional de Saúde (2012). Resolução nº 466, de 12 de dezembro de 2012. Brasília. Recuperado de https://bit.ly/3f97dc5

Conselho Nacional de Saúde (2016). Resolução n. 510, de 07 de abril de 2016. Brasilia. Recuperado de https://bit.ly/2XPYXYO

Cramer, L., Capelle, M., Andrade, A., \& Brito, M. (2012) Representações Femininas da Ação Empreendedora: Uma análise da trajetória das mulheres. Revista de Empreendedorismo e Gestão de Pequenas Empresas, 1(1), 53-71. https:// doi.org/10.14211/regepe.v1i1.14

Dean, H., Larsen, G., Ford, J., \& Akram, M. (2019). Female Entrepreneurship and the Metanarrative of Economic Growth: A Critical Review of Underlying Assumptions. International Journal of Management Reviens, 21(1), 24-49. https://doi.org/10.1111/ijmr.12173

DeMartino, R., \& Barbato, R. (2003). Differences Between Women and Men MBA Entrepreneurs: Exploring family flexibility and wealth creation as career motivators. Journal of Business Venturing, 18(6), 815-832. https://doi. org/10.1016/S0883-9026(03)00003-X

Falaster, C., Ferreira, M. P., \& Reis, C. (2015). Atributos que Atraem a Geração Y na Escolha do Emprego Ideal: Uma análise a partir da perspectiva de estudantes veteranos. Contextus - Revista de Economia e Gestão, 13(3), 7-31. https://doi.org/10.19094/contextus.v13i3.595

Global Entrepreneurship Monitor - GEM (2017). Report on Women's Entrepreneurship. Boston: The Fenway Group. Recuperado de https://bit. $\mathrm{lv} / 2 \mathrm{mi0} \mathrm{nL}$

Global Entrepreneurship Monitor - GEM. (2018). Empreendedorismo no Brasil. IBPQ. Recuperado de https://bit.ly/2kkzwgS

Gupta, V. K., Wieland, A. M. \& Turban, D. B. (2019). Gender Characterizations in Entrepreneurship. Journal of Small Business Management, 57(1), 131-153. https://doi.org/10.1111/jsbm.12495

Henry, C., Foss, L., \& Ahl, H. (2016). Gender and Entrepreneurship Research: A review of methodological approaches. International Small Business Journal, 34(3), 217-241. https://doi.org/10.1177/0266242614549779

Instituto Brasileiro de Geografia e Estatística - IBGE (2017a). Estatísticas do Empreendedorismo. Recuperado de https://biblioteca.ibge.gov.br/index.php/ biblioteca-catalogo? view $=$ detalhes

Instituto Brasileiro de Geografia e Estatística - IBGE (2017b). Censo Demográfico 2010 por Estado: Trabalho - Amostra. Recuperado de www.ibge.gov.br/ estadosat/

Instituto Brasileiro de Geografia e Estatística - IBGE (2015). Pesquisa Nacional por Amostra de Domicílios. Recuperado de https://bit.ly/2kPyFVB

Jonathan, E. G. (2011). Mulheres Empreendedoras: O desafio da escolha do empreendedorismo. Psicologia Clínica, 23(1), 65-85. https://doi.org/10.1590/ $\underline{\mathrm{S} 0103-56652011000100005}$

Loiola, E., Gondim, S. M. G., Pereira, C. R., \& Ferreira, A. S. M. (2016). Ação planejada e Intenção Empreendedora entre Universitários: Analisando preditores e mediadores. Revista Psicologia: Organizações e Trabalho, 16(1), 22 35. Recuperado de https://bit.ly/2YmaSwa

Machado, H. V., St-Cyr, L., Mione, A., \& Alves, M. C. M. (2003). O Processo de Criação de Empresas por Mulheres. Revista de Administração Eletrônica, 2(2), 1-22. https://doi.org/10.1590/S1676-56482003000200007

Mainiero, L., \& Sullivan, S. (2005). Kaleidoscope Careers: An alternate explanation for the "opt-out" revolution. The Academy of Management Executive, 19(1), 106-123. https://doi.org/10.5465/AME.2005.15841962

Marlow, S. (2014). Exploring Future Research Agendas in the Field of Gender and Entrepreneurship. International Journal of Gender and Entrepreneurship, 6(2), 102-120. https://doi.org/10.1108/IJGE-01-2013-0003

Martí, A. R., Porcar, A., \& Tur, A. M. (2014). Linking Female Entrepreneurs' Motivation to Business Survival. Journal of Business Research, 68(4), 810-814. https://doi.org/10.1016/j.jbusres.2014.11.033

Matte, J., Voltz, T., Schneider A., Miri, D., Chais, C., Ganzer P., Radaelli, A., Olea, P. (2019). Comportamento Empreendedor Feminino: Estudo no Estado do Rio Grande do Sul. Revista de Micro e Pequenas Empresas da Fatec, 1(5), 03-23. https://doi.org/10.21574/remipe.v5i1.137
Monteiro, R., Silveiro, C., \& Daniel, F. (2015). Representações Sociais do Empreendedorismo no Feminino e no Masculino: Investigação com estudantes. Psicologia em Estudo, 20(1), 107-116. https://doi.org/10.4025/ psicolestud.v20i1.25539

Muniz, J., \& Veneroso, C. (2019). Diferenciais de Participação Laboral e Rendimento por Gênero e Classes de Renda. Dados, 62(1), e20180252. Epub 18 de Abril, 2019. https://doi.org/10.1590/001152582019169

Nascimento, S. D. (2016). Precarização do Trabalho Feminino: A realidade das mulheres no mundo do trabalho. Revista Políticas Públicas, 20(1), 339-346. Recuperado de https://bit.ly/30qfxQx

Oliveira, M. Z., Barbosa, P. V., \& Gauer, G (2012). Avaliação de Medidas Implícitas e de Carreira e Gênero. Psico, 43(4), 452-462. Recuperado de https://bit.ly/2AZ83cr

Oliveira, I. R., Camargo, M. L., Feijó, M. R., Campos, D. C., \& Goulart J. E. (2016). Empreendedorismo Social, Pós-Modernidade e Psicologia. Revista Interinstitucional de Psicologia, 9(2), 290-311. Recuperado de https://bit. ly/2Ut8ouU

Oliveira, J. H. A. (2017). Empreendedorismo Feminino - uma revisão dos artigos de maior impacto na literatura internacional entre os anos de 2010 e 2017. South American Development Society Journal, 3(09), 235-248. http://doi. org/10.24325/issn.2446-5763.v3i9p235-248

Ramos, K. de S., \& Valdisser, C. R. (2019). Das Dificuldades ao Sucesso: Os caminhos tortuosos e cheios de obstáculos enfrentados por empreendedoras. Revista GeTeC, 8(20), 23-40. Recuperado de https://bit. ly/2AU49BI

Roy, S., \& Manna, S. (2014). Women in Entrepreneurship: Motivation and choice of business. Journal of Entrepreneurship and Management, 3(2), 1-8. Recuperado de https://bit.ly/3dO1lVx

Schneider, K. (2017). Promoting the Entrepreneurial Success of Women Entrepreneurs through Education and Training. Science Journal of Education, 5(2), 50-59. https://doi.org/10.11648/j.sjedu.20170502.13

Serviço Brasileiro de Apoio às Micro e Pequenas Empresas - SEBRAE (2015). Anuário das Mulberes Empreendedoras e Trabalhadoras em Micro e Pequenas Empresas, 3. Ed, Brasília: DIEESE. Recuperado de https://bit.ly/2XN4cZ1

Sousa, L. P., \& Guedes, D. R. (2016). A Desigual Divisão Sexual do Trabalho: Um olhar sobre a última década. Estudos Avançados, 30(87), 123-139. https://doi. org/10.1590/S0103-40142016.30870008

Strobino, M. R. C., \& Teixeira, R. M. (2014). Empreendedorismo Feminino e o Conflito Trabalho-Família: Estudo de multicasos no setor de comércio de material de construção da cidade de Curitiba. Revista Administração, 49(1), 59-76. https://doi.org/10.5700/rausp1131

Sullivan, D. M., \& Meek, W. R. (2012). Gender and Entrepreneurship: A review and process model. Journal of Managerial Psychology, 27(5), 428-458. https:// doi.org/10.1108/026839412112353

Sullivan, S. E., \& Baruch, Y. (2009). Advances in Career Theory and Research: A critical review and agenda for future exploration. Journal of Management, 35(6), 1542-1571. https://doi.org/10.1177/0149206309350082

Sullivan, S. E., Forret, M. L., Carraher, S. M., \& Mainiero, L. A. (2009). Using the Kaleidoscope Career Model to Examine Generational Differences in Work Attitudes. Career Development International, 14(3), 284-302. https://doi. org/10.1108/13620430910966442

Stein, G., Sulzbach, V., \& Bartels, M. (2015). Relatório sobre o Mercado de Trabalho do Rio Grande do Sul - 2001-13. Porto Alegre: FEE. Recuperado de https://bit. $\mathrm{lv} / 2 \mathrm{znfH} 02$

Vale, G. M. V., Corrêa, V. S., \& Reis, R. F. (2014). Motivações para o Empreendedorismo: Necessidade versus oportunidade?. Revista de Administração Contemporânea, 18(3), 311-327. https://doi.org/10.1590/19827849rac20141612

\section{Informações sobre os autores:}

\section{Patrícia Bock Bandeira}

CAPE - Av. Mariland, 907, sala 802 - CEP 90440-191 - Porto

Alegre/RS, Brasil.

E-mail: patricia@capepsi.com.br

\section{Marcos Vinicius Amorim}

E-mail: vmarcosamorim@gmail.com

\section{Manoela Ziebell de Oliveira}

E-mail: manoela.oliveira@pucrs.br 